\title{
The Importance of the Zagros Mountains Barrier Jet to Future Precipitation in the Fertile Crescent
}

\author{
J.P. Evans ${ }^{*}$ and A. Alsamawi
}

\author{
Climate Change Research Centre, University of New South Wales, Sydney, NSW, 2502, Australia
}

\begin{abstract}
This study quantifies the significance of southerly water vapour fluxes, associated with the Zagros Mountains barrier jet, on precipitation occurring in the Eastern Fertile Crescent region and its change due to global warming. Precipitation events are simulated using a Regional Climate Model (MM5-Noah) driven by boundary conditions from a CCSM global climate model simulation with the SRES A2 emission scenario. The precipitation events were grouped into classes based on the similarity of their water vapour fluxes. Results show a massive increase in the southerly dominated classes which are associated with the formation of a barrier jet on the western slopes of the Zagros Mountains. This increase was related to an increase in atmospheric water vapour in the southern portion of the domain rather than to an increase in the frequency of formation or wind speed of the barrier jet itself. The presence of this barrier jet becomes increasingly important to precipitation in the Eastern Fertile Crescent region as global warming progresses. Thus, low resolution models that are unable to capture this phenomena will produce questionable future projections for this region.
\end{abstract}

Keywords: Regional climate modelling, middle east, mountain barrier jet, precipitation, climate change.

\section{INTRODUCTION}

The Fertile Crescent is defined here as an area encompassing south-east Turkey, north-eastern Syria, northern Iraq and north-western Iran and is shown in Fig. (1, it is the eastern half of the full Fertile Crescent). The area of interest covers approximately $20,000 \mathrm{~km}^{2}$. It is centred over a large precipitation maxima found in both data and model results and includes most of the headwaters of the Euphrates and Tigris Rivers, hence precipitation here is an important source of fresh water for parts of Turkey, Syria and Iraq. Being a dominantly arid area relatively little precipitation recycling occurs over the land and the surrounding water bodies are major contributors to atmospheric water vapour. To the north-west is the Black Sea, north-east is the Caspian Sea, to the west is the Mediterranean and to the south is the Persian Gulf. Earlier modelling work (Evans et al. [1]; Evans and Smith [2]) indicated that water vapour contributing to some of the storms in this area are dominated by a southerly flux. In fact, Evans and Smith [2] showed that though a relatively small number of events are dominated by southerly fluxes, these events are very large and hence any change in the numbers of these events can have a significant impact on the fresh water resources within the Euphrates-Tigris watershed. These southerly fluxes are significantly enhanced by the formation of a barrier jet along the slopes of the Zagros Mountains. Work by Marcella and Eltahir [3] on the variability of Kuwait rainfall found similar influences from both the tropics (southern) and midlatitudes (Western).

Growing acceptance of the reality of global warming has recently led to an increase in the publication of studies related to global warming impacts. Many Global Climate

\footnotetext{
*Address correspondence to this author at the Climate Change Research Centre, University of New South Wales, Sydney, NSW, 2502, Australia; Fax: +61-2-9385 7123; E-mail: jason.evans@unsw.edu.au
}

Model (GCM) simulations were performed as part of the IPCC AR4 and the resulting model output has been made available through the Earth System Grid (http://www.earthsy stemgrid.org/home/home.htm) for use in impacts studies. Some of these studies focus on global changes in various phenomena that are important for the Middle East such as changes in storm tracks (Bengtsson et al. [4]; Lambert and Fyfe [5]), temperature (Min and Hense [6]) and drought (Wang [7]). Evans [8] presents the changes in climate predicted for the Middle East over the $21^{\text {st }}$ century by an ensemble of 18 GCMs using the Special Report on Emission Scenarios (SRES) A2 emission scenario which is the scenario closest to a "business as usual" scenario in the SRES family. That study found an increase in temperature for the region of almost $4 \mathrm{~K}$ by late century, along with significant changes in precipitation that include a decrease in an area stretching from Turkey and the Eastern Mediterranean across to North-eastern Iran, and an increase over much of the Persian Gulf and Saudi Arabia. Various aspects of the performance of CCSM3, the GCM used to provide boundary conditions in this study, under different emission scenarios can be found in Meehl et al. [9].

Evans [10] investigated changes in precipitation causing mechanisms for various regions within the Middle East, due to global warming. A small increase in precipitation was predicted for the Fertile Crescent with the dominant precipitation mechanism being less associated directly with storm tracks and more associated with upslope flow of water vapour. Along with changes in the amount and causing mechanisms for precipitation in the Fertile Crescent, one may expect changes in the water vapour pathways and source regions leading to this precipitation. Changes in the water vapour transport was investigated in Evans [11]. This study investigates these later changes using a Regional Climate Model (RCM) run under present day and future increased greenhouse gas conditions. In particular the role 


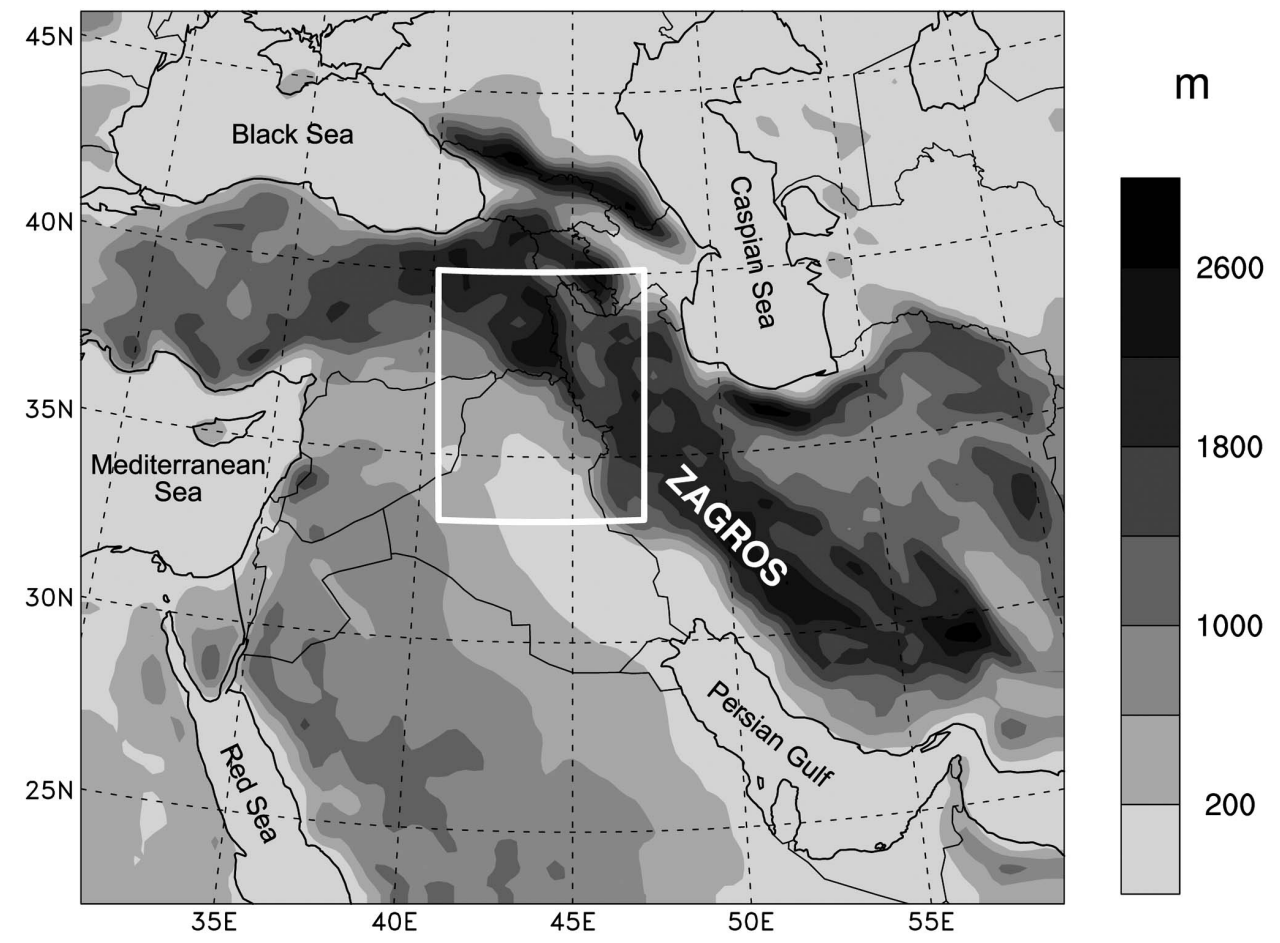

Fig. (1). Topography of regional climate model domain (Fertile Crescent study area is outlined in white).

played by the mountain barrier jet on how this changes in the future is examined. Onol and Semazzi [12] also used a regional climate model to investigate the climate change impacts in the region. They found an increase in the Autumn rainfall which was associated with an increase in the southerly wind in agreement with Evans [11]. Kitoh et al. [13] used a high resolution global model to investigate future climate changes in the Middle East finding a general decrease in annual precipitation in the Fertile Crescent though they did not investigate the changes at higher temporal resolution.

This paper investigates the role played by the Zagros mountains barrier jet in producing the Fertile Crescent changes found in Evans [11]. In doing so this paper seeks to answer several questions not previously investigated. How important is the barrier jet to the transport of water vapour into the Fertile Crescent? What causes the apparent increase in barrier jet related precipitation in the future? Does the barrier jet form more often? Does it have stronger wind speeds? Or carry more moisture? Given the barrier jet is important for the climate of this region, can even high resolution Global models capture some of its effects?

The climate models and simulations used here are described in section 2 . The precipitation events are clustered according to the water vapour fluxes into and out of the region (section 0 ) with the results of the study presented in sections 0 . The conclusions of the study are presented in section 0 .

\section{CLIMATE MODEL AND SIMULATION DESCRIPTION}

This study examines the global warming caused changes in the water vapour transported within a mountain barrier jet in the Middle East. To accomplish this, the output from a GCM simulation is downscaled using an RCM and the output from these RCM simulations is used to investigate the connection between water vapour transport and the precipitation in the Fertile Crescent.

\subsection{Global Climate Model (CCSM3)}

The Community Climate System Model version 3 (CCSM3) is a coupled climate model developed and maintained through the National Center for Atmospheric Research (NCAR) in the USA and described in Collins et al. [14]. The model couples components that model the atmosphere, ocean, sea ice and land surface. The simulation used in this study came from a T85 version of CCSM3 and is described in detail in Meehl et al. [9]. In short the model has atmospheric grid points roughly every $1.4^{\circ}$ latitude and longitude and 26 levels in the vertical. The ocean is modelled on a nominal $1^{\circ}$ grid with 40 levels in the vertical. No flux adjustment is used. Atmospheric composition is in accordance with the SRES A2 emission scenario for the $21^{\text {st }}$ century.

\subsection{Regional Climate Model (MM5-Noah)}

The PSU/NCAR (Pennsylvania State University / National Center for Atmospheric Research) mesoscale modeling system MM5 is described in Dudhia [15] and Grell et al. [16]. MM5 is a limited-area nonhydrostatic model that uses a terrain-following vertical coordinate system. It has 2way nesting capabilities, and flexible physics options. In this study MM5 was implemented with the Reisner Mixed-Phase explicit moisture scheme (Reisner et al. [17]), the MRF planetary boundary layer scheme (Hong and Pan [18]), the Rapid Radiative Transfer Model (RRTM) radiation scheme (Mlawer et al. [19]) and the Grell scheme for convective precipitation (Grell et al. [16]).

MM5 is operationally linked with the Noah Land Surface Model (LSM). Noah is a direct descendent of the Oregon State University (OSU) LSM (Mahrt and Ek [20]; Mahrt and 
Pan [21]; Pan and Mahrt [22]), a sophisticated land surface model that has been extensively validated in both coupled and uncoupled studies (Chen and Dudhia [23]; Chen and Mitchell [24]). The Noah LSM simulates soil moisture, soil temperature, skin temperature, snowpack depth and water equivalent, canopy water content, and the energy flux and water flux terms of the surface energy balance and surface water balance. In its MM5-coupled form Noah has a diurnally dependent Penman potential evaporation (Mahrt and Ek [20]), a four layer soil model (Mahrt and Pan [21]), a primitive canopy model (Pan and Mahrt [22]), modestly complex canopy resistance (Jacquemin and Noilhan [25]), and a surface runoff scheme (Schaake et al. [26]).

MM5 has been applied successfully at grid cell resolutions ranging from greater than $100 \mathrm{~km}$ to less than 1 $\mathrm{km}$ and is used for weather forecasts, climate research (Zaitchik et al. [27]; Evans et al. [28]) and process studies (Zaitchik et al. [29,30]). Here we apply the model at $27 \mathrm{~km}$ horizontal resolution and 23 vertical levels over a domain which includes much of the Middle East and the surrounding water bodies. Fig. (1) shows the model domain excluding the rows and columns which are directly influenced by the boundary conditions. Previously RCM simulations over the same domain were performed using RegCM2 (Evans et al. [1]) and MM5 (Evans and Smith [2]) for the early 1990s. These simulations showed good agreement with observations, with the MM5 performing best.

In this study three MM5 simulations are discussed. Two of these simulations cover the 5 year period 2000 through 2004. One of these runs uses initial and boundary conditions from the NCEP/NCAR reanalysis (Kistler et al. [31]), denoted MM5/NNRP, and the other from the CCSM3 simulation performed for the IPCC AR4 using the SRES A2 emission scenario, denoted MM5/CCSM 2000. The third simulation covers the 5 year period 2095 through 2099, with initial and boundary conditions coming from the same CCSM3 SRES A2 simulation, denoted MM5/CCSM 2095. In each case the first 2 months of the MM5 simulation is considered "spin-up" and relevant statistics are calculated using the remaining time of the model run. Evaluation of the RCM model performance for the simulation used here can be found in (Evans [10]).

\section{PRECIPITATION EVENT CLASSIFICATION}

Using the method described in Evans and Smith [2], the Fertile Crescent events are clustered based on the fluxes through the sides of the box shown in Fig. (1). Each event is represented by a data series consisting of a three hourly flux series from each direction (North, South, East, and West) and the precipitation series. These series extend from one day before, until one day after the time of peak precipitation. The use of all the major fluxes guarantees that the complete data series has a mean close to zero regardless of the size of event and removes the potential for the clustering algorithm to cluster points based on differences in their means.

This clustering is performed using the iterative clustering algorithm ISODATA (Ball and Hall [32]) applied to the above data series for the 200 largest precipitation events over the five year period. In total they account for $\sim 72 \%$ of all the precipitation falling within the box indicated in Fig. (1) over the five year period for the MM5/NNRP simulation. The algorithm was run using statistical initialization starting with between eight and twelve classes. In all cases only six classes of events, with a minimum of five members, were produced by the algorithm. That is, the algorithm found it necessary to merge classes due to their similarity until only six classes remained.

Once the classes are established using the ISODATA algorithm applied to the MM5/NNRP simulation results, a minimum Euclidean distance algorithm is used to assign events from the two CCSM based simulations into these classes.

\section{RESULTS}

The mean water vapour fluxes for each of the classes are presented in Fig. (2). Two of these event classes, 4 and 6, are dominated by southerly fluxes and are the events focused on in this study. Fig. (4) shows the water vapour flux through the vertical cross section along the southern boundary of the box seen in Fig. (1), for classes 4 and 6. A large maximum in the flux can be seen just windward of the Zagros Mountains associated with a barrier jet there in the MM5/NNRP simulation (Fig. 3c, d). In all cases $\sim 90 \%$ of the water vapour flux is transported within the barrier jet rather than the surrounding atmosphere. Since the classes are derived based on the MM5/NNRP data, without any CCSM driven data, it is not expected that the CCSM results will precisely reproduce the class characteristics found for MM5/NNRP. They do however maintain the key features associated with the barrier jet as discussed below.

For class 4 events this barrier jet is closely coupled to the mountain slope with a maxima at around $900 \mathrm{hPa}$ height. Both MM5/CCSM simulations show a similar jet structure though it is less intense at its core and shifter slightly higher. In the MM5/CCSM 2095 simulation the class 4 events are elevated further from the ground and extend deeper into the atmosphere. Fig. (3a) shows the barrier jet water vapour flux through time for each simulation. Overall the simulations follow a similar evolution with the MM5/NNRP producing a higher peak flux than the MM5/CCSM simulations. Comparing the MM5/CCSM simulations shows that at late century class 4 events have a slightly higher peak flux and a generally higher flux throughout most of the following day.

In Fig. (3d) it can be seen that class 6 events have the southerly flow over a broader area with the strongest flow centred at $800 \mathrm{hPa}$ height. The enhancement of the flow due to the barrier jet is much weaker for class 6 than class 4 . Comparison with the water vapour flux produced by the MM5/CCSM simulations shows a considerable variation in the vertical structure of the class 6 water vapour flux. Fig. (3b) shows that MM5/CCSM 2000 produces a peak flux that is considerably lower than that produced in either of the other simulations. Overall significantly more water vapour moves into the area in a single class 6 event late in the century compared to the present.

Several quantitative conclusions can be drawn from the number and size of events in each class as presented in Table 1. The control simulation (MM5/NNRP) placed $9.5 \%$ of events in these classes and they accounted for a total of $24.7 \%$ of the precipitation. So while these southerly flux dominated events are relatively rare they tend to be particularly large events and hence hold particular 

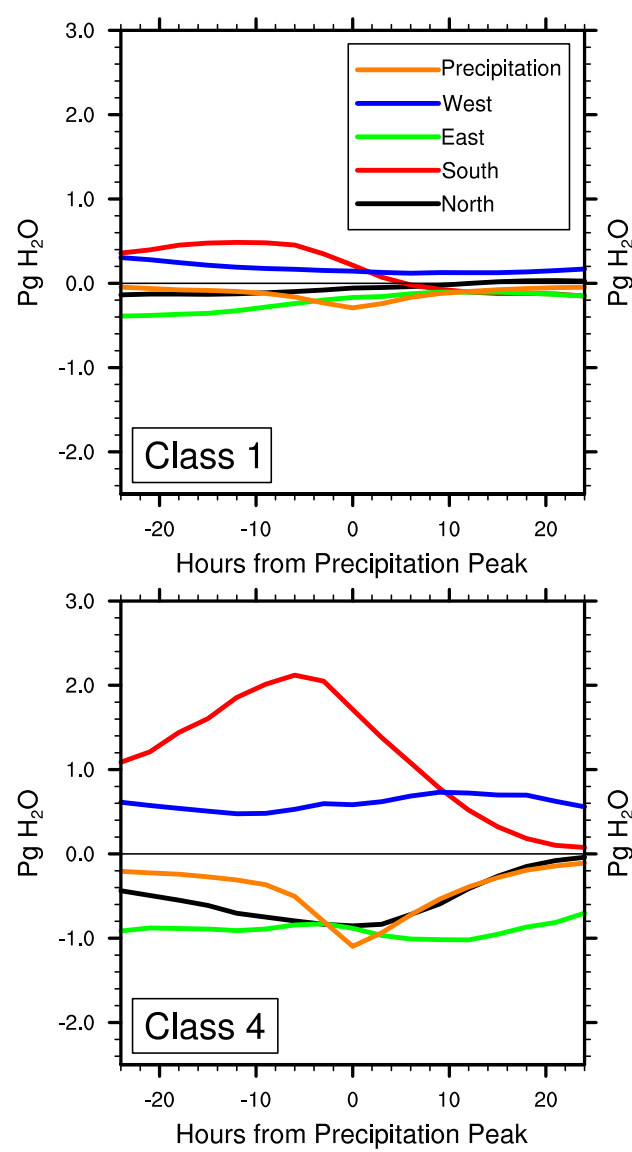
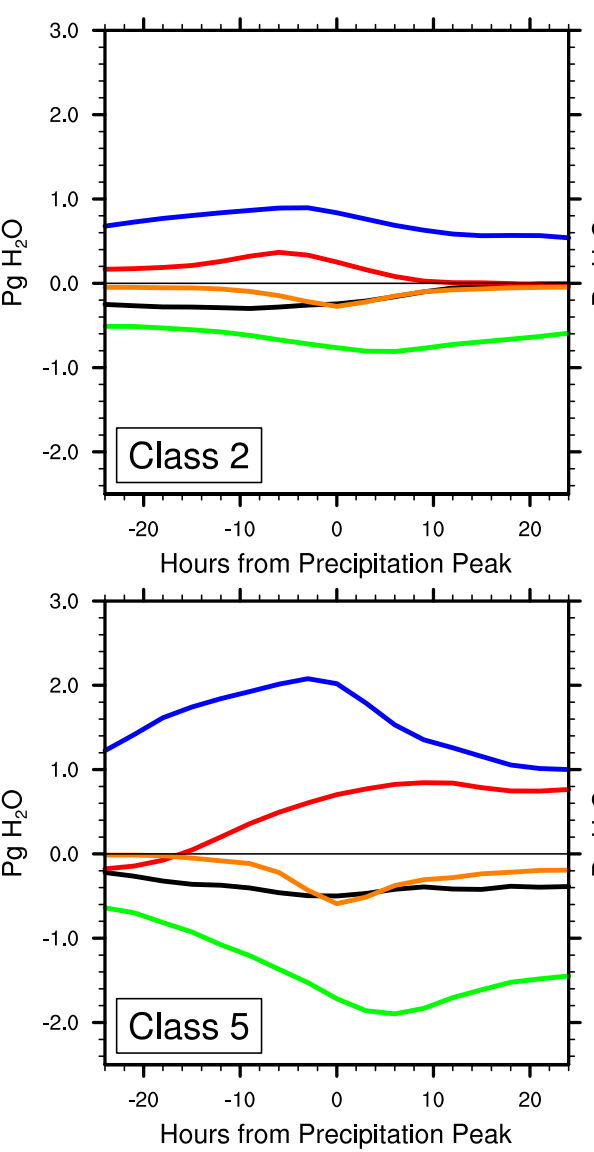
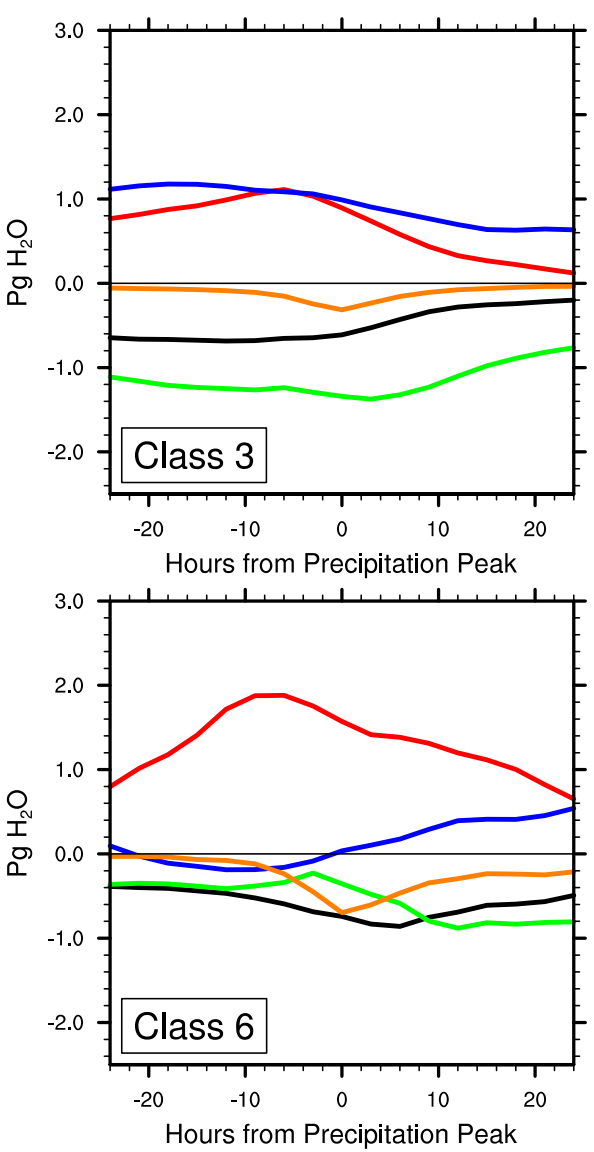

Fig. (2). The six water vapour flux based precipitation event classes.

importance for precipitation in the Fertile Crescent region as discussed previously (Evans and Smith [2]). Results from the global warming simulations show the frequency of these events increasing from $8.5 \%$ in the MM5/CCSM 2000 simulation to $26 \%$ in the MM5/CCSM 2095 simulation. This increase in frequency is accompanied by an increase in the total precipitation percentage from $19.3 \%$ to $57.4 \%$.

It is hypothesized that these large changes may be caused by some combination of two mechanisms: increased frequency of the formation and strength of the barrier jet; and/or increased amount and residence time of the low level water vapour that feeds into the jet. By defining the barrier jet to have formed if the upper level flow is dominantly upslope while the low level flow is dominantly along slope (and into the box), and the strength given simply by the mean low level wind speed when a barrier jet is present then for the MM5/CCSM 2000 simulation the barrier jet forms on $19.4 \%$ of days while for the MM5/CCSM 2095 simulation the barrier jet forms on $20.3 \%$ of days. The change in wind fields can be seen in Fig. (4). All simulations show the characteristic high wind speeds at low levels just west of the mountains indicative of a barrier jet. Fig. $(\mathbf{4 a}, \mathbf{b})$ indicate that the future simulation (MM5/CCSM 2095) has consistently lower wind speeds to the simulation of the present. Clearly these changes in barrier jet strength and frequency cannot explain the large increase in frequency of the southerly dominated precipitation events.

Investigating changes in the water vapour mixing ratio in the barrier jet region reveals the MM5/CCSM 2000 simulation to have a dry bias in the south when compared to the MM5/NNRP simulation for these barrier jet events (Fig. 5). The future simulations consistently have higher mixing ratios than the present day simulations. This increase in low level water vapour produces increases in precipitable water which can be seen throughout the southern portion of the domain (Fig. 6). The increase begins in spring but is most pronounced in summer and autumn. This matches the seasonality of the changes in class 4 and 6 events with increases in both the number of events occurring in spring and autumn, with the largest increase being the increase in class 6 events in autumn. Along with this increase in the total water available there is also an increase in relative humidity of $\sim 15 \%$. Thus this significant increase in the presence of low level water vapour means that when the barrier jet forms it is much more likely to have water vapour available to transport and hence increase the frequency of these southerly dominated precipitation events. This increase in atmospheric water is related to the northward movement of the InterTropical Convergence Zone (ITCZ) which is a robust feature of the Global Climate Model simulations submitted to the recent IPCC report (Evans [8]). This means that the area experiences a weaker downward branch of the Hadley cell through the transition and summer seasons, increasing the planetary boundary height by $200 \mathrm{~m}$ or more and allowing greater vertical mixing and more vigorous surface evaporation. These results also concur with those presented in Evans [10] which found that storm track location (associated with Westerly dominated events) was the dominant precipitation causing mechanism at present while 

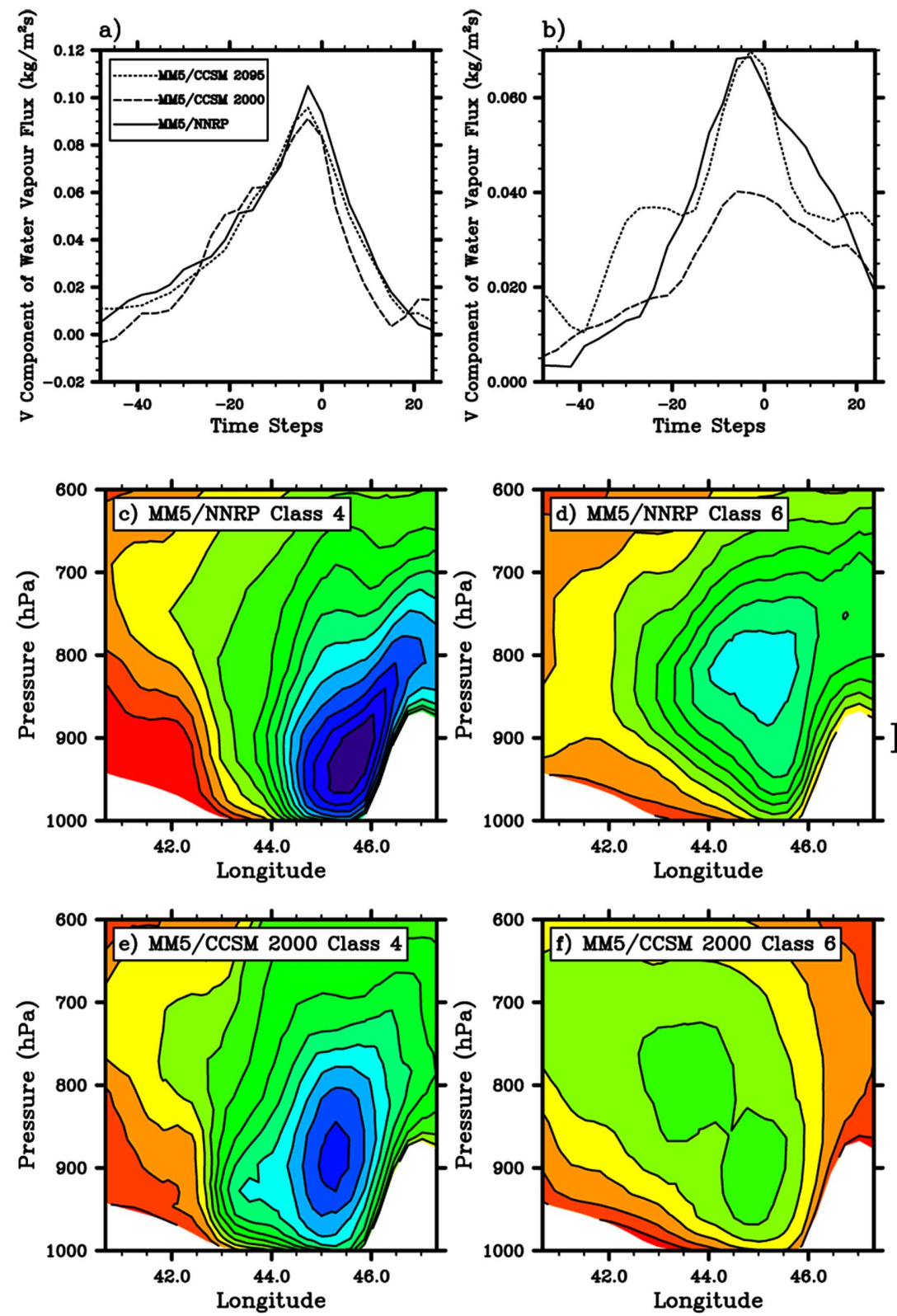

$\mathrm{kg} / \mathrm{m}^{2} \mathrm{~s}$
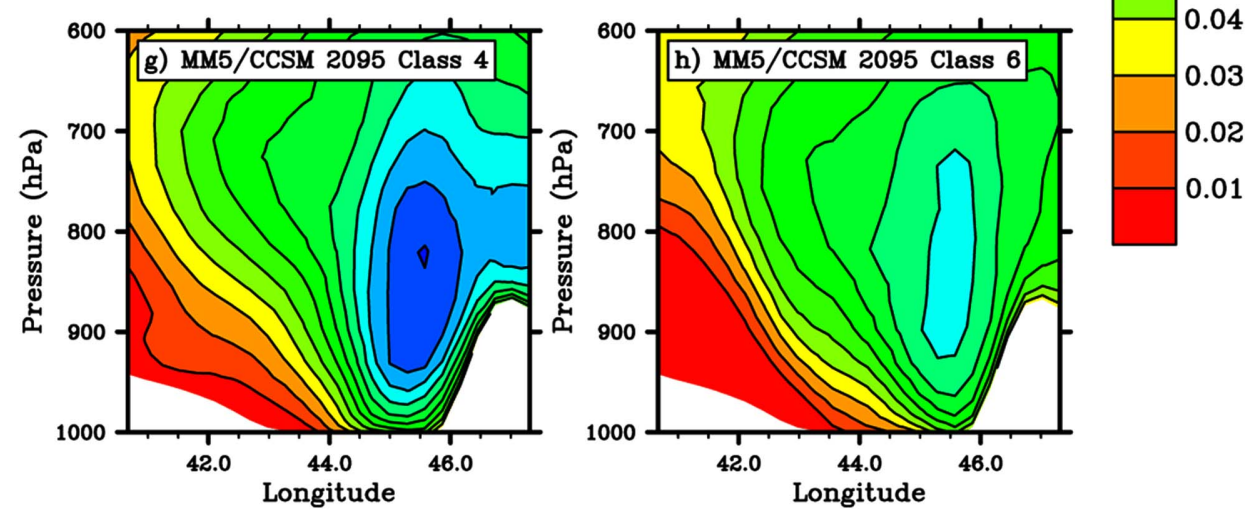

Fig. (3). Time series of the water vapour flux entering the Fertile Crescent box from the south for classes 4 (a) and 6 (b). Vertical cross section of the water vapour flux crossing the South side of the Fertile Crescent box, 3 hours before the precipitation peak for classes 4 and 6 (c-h) (topography is shown in white).

by the end of the century, upslope flow (associated with southerly dominated events) becomes an increasingly important mechanism.
The GCM ensemble presented in Evans [8] shows no indication of these barrier jet related events. However, an ensemble of only the highest resolution GCM simulations 

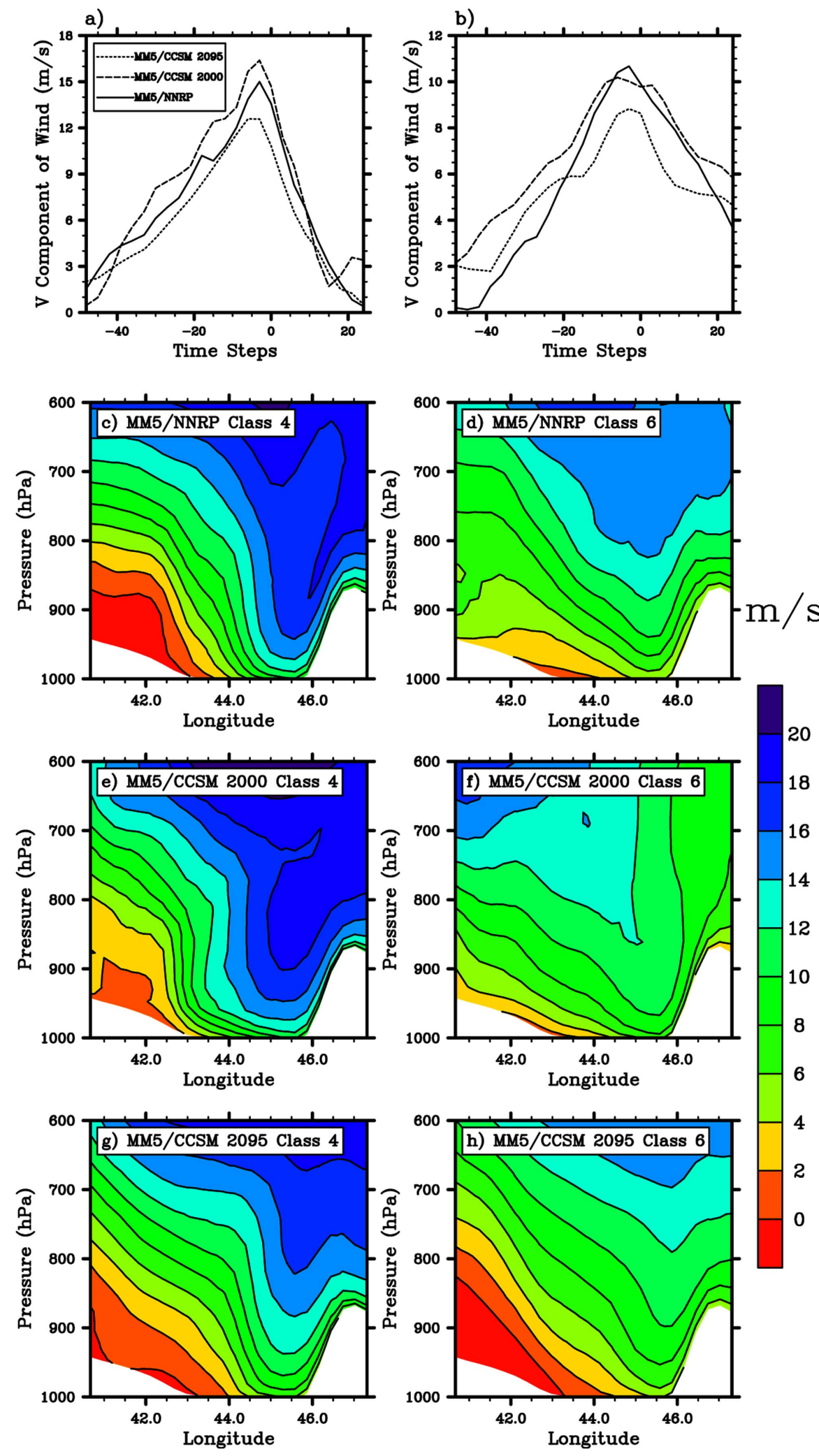

Fig. (4). Time series of water vapour mixing ratio in the barrier jet region (a \& b). Vertical cross section of the mixing ratio for each simulation (c to $\mathbf{h})$. White indicates topography.

(CCSM3 and HadGEM1) indicates an increase in precipitation for most of Iraq with a weak decrease in the north and the main area of decreasing precipitation confined to Turkey and the Eastern Mediterranean. Thus they project a change in precipitation that lies between the all GCM ensemble and the high resolution RCM. This may indicate that even at $\sim 1.5^{\circ}$ resolution the GCMs are better able to capture the influence of topography even if they are still too coarse to capture phenomena like the mountain barrier jet. 
Table 1. Percent of Events (Percent Precipitation) for Each Class and Simulation (Evans, 2008)

\begin{tabular}{|c|c|c|c|}
\hline \multirow{2}{*}{ Class } & \multicolumn{3}{|c|}{ \% of Events (\% Total Precipitation) } \\
\cline { 2 - 4 } & MM5/NNRP & MM5/CCSM 2000 & MM5/CCSM 2095 \\
\hline \hline 4 & $6(18.3)$ & $2(10.7)$ & $11.5(27.4)$ \\
\hline 6 & $3.5(6.4)$ & $6.5(8.6)$ & $14.5(30)$ \\
\hline
\end{tabular}

This study suggests that capturing the barrier jet, and its related precipitation events, is vital to correctly capturing the climate of the Fertile Crescent. It also suggests that events related to this phenomena are likely to reduce, or at times reverse, the precipitation decrease projected by GCMs in the IPCC Fourth Assessment report and Evans [8]. This would have significant implications for water resources in the region. Perhaps the largest impact being that future precipitation is projected to arrive more often in large storm
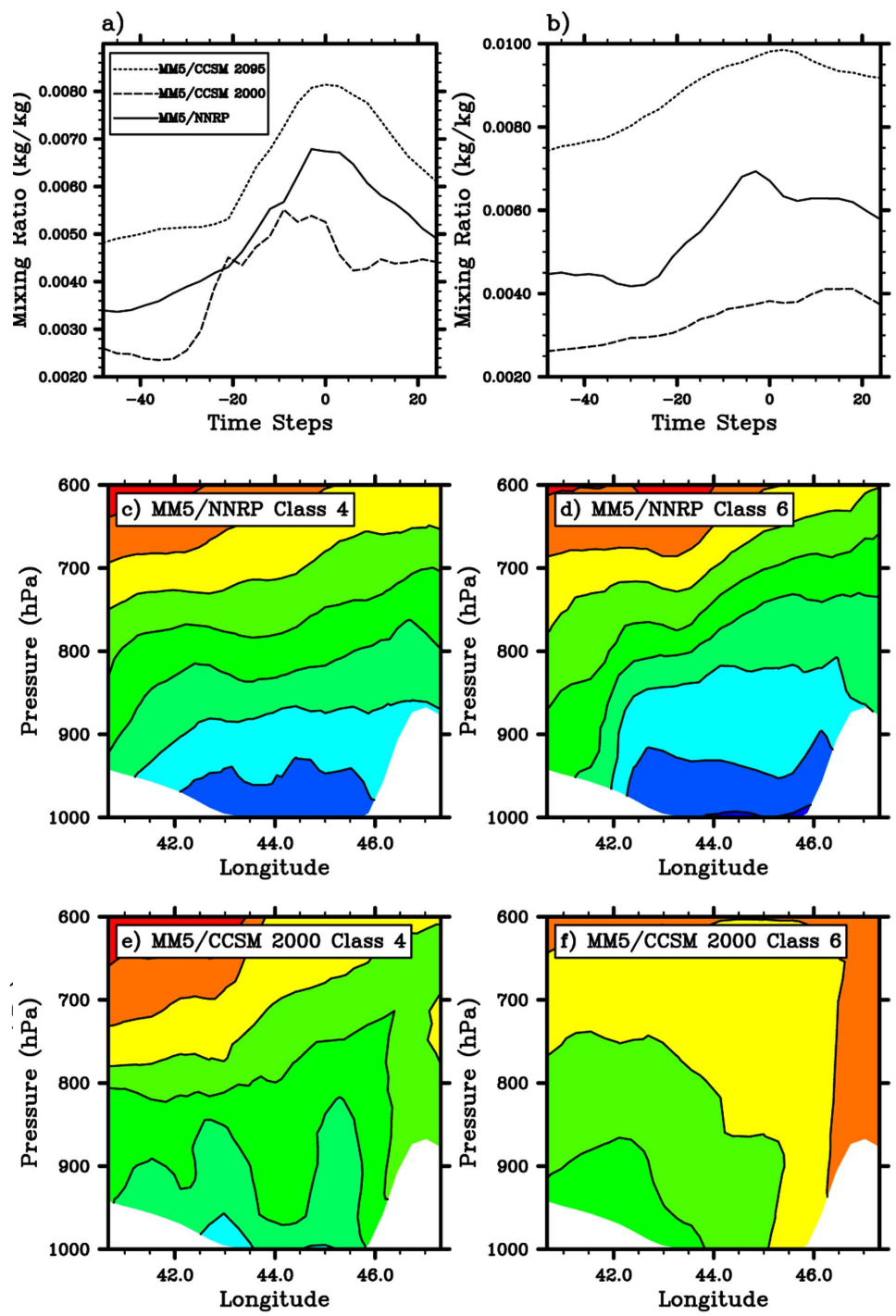

$\mathrm{kg} / \mathrm{kg}$
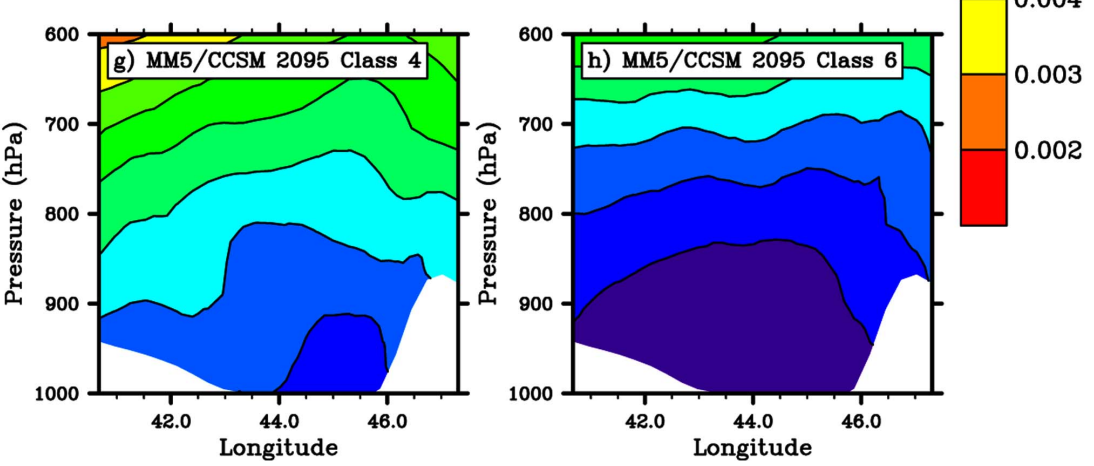

Fig. (5). Times series of mean wind speed in the barrier jet for each class (a \& b). Vertical structure of wind fields for each class (c to h). White indicates topography. 

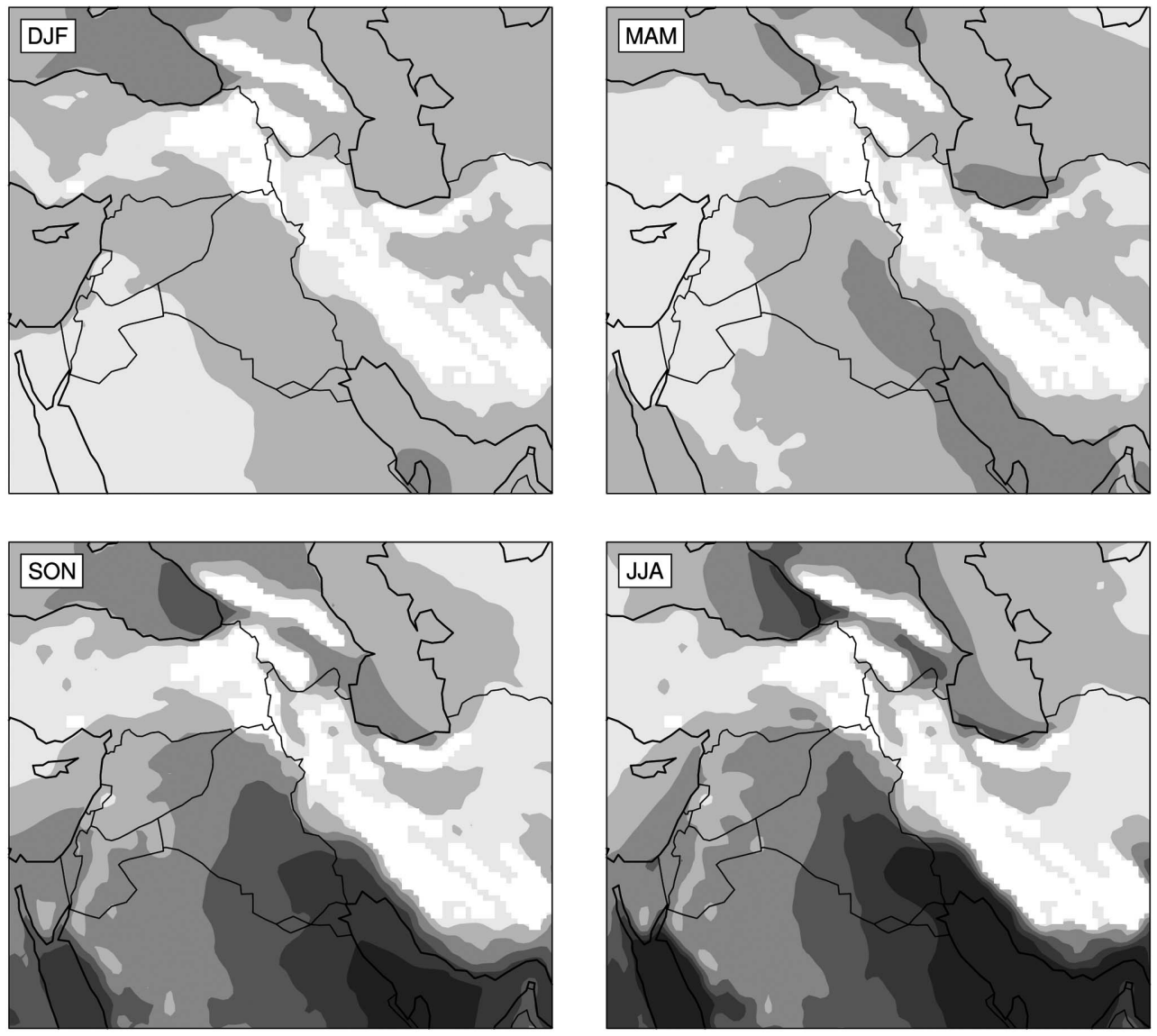

$\mathrm{mm}$

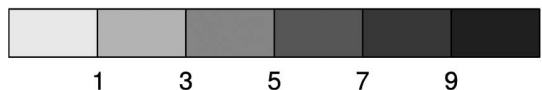

Fig. (6). Change in precipitable water below $800 \mathrm{hPa}(2095$ - 2000) for each season. White indicates regions below terrain.

events with significant dry periods in-between, requiring sophisticated management approaches that address increased flood and erosion risks while improving storage capacity to maintain supply through the dry periods. This needs to be shown with several other models before the conclusion can be considered robust. New international projects designed to inform the $5^{\text {th }}$ IPCC assessment report such as the COordinated Regional climate Downscaling EXperiment (CORDEX) will provide a multi-model test of these findings.

\section{CONCLUSION}

The study presented here quantifies the significance of southerly water vapour fluxes, associated with the Zagros Mountains barrier jet, on precipitation occurring in the Eastern Fertile Crescent region. The water vapour fluxes were investigated at high temporal and spatial resolution by using a Regional Climate Model (MM5-Noah) to downscale the NCEP/NCAR reanalysis. Using the ISODATA clustering algorithm the 200 largest precipitation events occurring during the first 5 years of the 2000s and accounting for over $70 \%$ of the entire precipitation, were grouped into classes based on the similarity of their water vapour fluxes.

The same RCM was run using boundary conditions from the CCSM global model for the first and last 5 years of the $21^{\text {st }}$ century using the SRES A2 emissions scenario. The resulting precipitation events were clustered using the classes found with reanalysis boundary conditions. Results show a massive increase in the southerly dominated classes which are associated with the formation of a barrier jet on the western slopes of the Zagros Mountains. The frequency of these events increases from $8.5 \%$ to $26 \%$, while accumulated magnitude of these events increases from $19.3 \%$ to $57.4 \%$ of the total precipitation. It was also found that this increase was related to an increase in atmospheric water vapour in the southern portion of the domain rather than to an increase in the frequency of formation of the barrier jet itself. The results also suggest that GCMs need to resolve this barrier jet in order to capture its influence on future precipitation in the Fertile Crescent region. This is likely true for other mountainous regions of the world where barrier jets form often enough to influence the local climate.

\section{ACKNOWLEDGEMENTS}

This study was undertaken with the financial support of NASA (NNG05GB36G) and NSF(ATM-0531212). We appreciate computer time for model runs provided by National Center for Atmospheric Research (NCAR). The research was motivated and assisted by many fruitful conversations with other members of the South-West Asia project team including Ron Smith, Roland Geerken, Frank Hole, Ben Zaitchik, and Larry Bonneau. CCSM data for 
boundary conditions were supplied through Oak Ridge National Lab with special thanks to David Erickson.

\section{CONFLICT OF INTEREST}

None declared.

\section{REFERENCES}

[1] Evans JP, Smith RB, Oglesby RJ. Middle East climate simulation and dominant precipitation processes. Int $\mathrm{J}$ Climatol 2004; 24:1671-94.

[2] Evans JP, Smith RB. Water vapor transport and the production of precipitation in the Eastern fertile crescent. J Hydrometeorol 2006; 7: 1295-307.

[3] Marcella M, Eltahir E. The hydroclimatology of Kuwait: explaining the variability of rainfall at seasonal and inter annual time scales, J Hydrometeorol 2008; 9(5):1095-105.

[4] Bengtsson L, Hodges KI, Roeckner E. Storm tracks and climate change. J Climate 2006; 19(15): 3518-43.

[5] Lambert SJ, Fyfe JC. Changes in winter cyclone frequencies and strengths simulated in enhanced greenhouse warming experiments: results from the models participating in the IPCC diagnostic exercise. Climate Dyn 2006; 26(7-8): 713-28.

[6] Min SK, Hense A. A Bayesian assessment of climate change using multimodel ensembles. Part I: Global mean surface temperature. J Climate 2006; 19(13): 3237-56.

[7] Wang G. Agricultural drought in a future climate: results from 15 global climate models participating in the IPCC 4th assessment. Climate Dyn 2005, 25(7-8): 739-53.

[8] Evans JP. 21st century climate change in the Middle East. Climatic Change 2009; 92: 417-32.

[9] Meehl GA, Washington WM, Santer BD, et al. Climate change projections for the twenty-first century and climate change commitment in the CCSM3. J Climate 2006; 19(11): 2597-616.

[10] Evans JP. Global warming impact on the dominant precipitation processes in the Middle East. Theor Appl Climatol 2010; 99: 389402.

[11] Evans JP. Changes in water vapor transport and the production of precipitation in the eastern fertile crescent as a result of global warming. J Hydrometeorol 2008; 9: 1390-401.

[12] Önol B, Semazzi F. Regionalization of climate change simulations over the eastern Mediterranean, J Climate 2009, 22(8), 1944-61.

[13] Kitoh A, Yatagai A, Alpert P. First super-high-resolution model projection that the ancient "Fertile Crescent" will disappear in this century. Hydrol Res Lett 2008; 2: 1-4.

[14] Collins WD, Bitz CM, Blackmon ML, et al. The community climate system model version 3 (CCSM3). J Climate 2006; 19(11): 2122-43.

[15] Dudhia J. A nonhydrostatic version of the Penn State / NCAR mesoscale model: Validation tests and simulation of an Atlantic cyclone and cold front. Mon Weather Rev 1993; 121: 1493-513.
[16] Grell GA, Dudhia J, Stauffer DR. A description of the fifthgeneration Penn State/NCAR mesoscale model (MM5). NCAR Tech. Note, NCAR/TN-398+STR. National Center for Atmospheric Research, Boulder CO. 1994; pp.117

[17] Reisner J, Rasmussen RJ, Bruintjes RT. Explicit forecasting of supercooled liquid water in winter storms using the MM5 mesoscale model. Q J R Meteorol Soc 1998; 124B: 1071-107.

[18] Hong SY, Pan HL. Nonlocal boundary layer vertical diffusion in a medium-range forecast model. Mon Weather Rev 1996; 124: 2322 39 .

[19] Mlawer EJ, Taubman SJ, Brown PD, Iacono MJ, Clough SA Radiative transfer for inhomogeneous atmosphere: RRTM, a validated correlated-k model for the longwave. J Geophys Res 1997; 102(D14): 16663-82.

[20] Mahrt L, Ek M. The influence of atmospheric stability on potential evaporation. J Climate App Meteorol 1984, 23: 222-34.

[21] Mahrt L, Pan HL. A two-layer model of soil hydrology. Boundary Layer Meteorol 1984; 29: 1-20.

[22] Pan HL, Mahrt L. Interaction beteen soil hydrology and boundarylayer development. Boundary Layer Meteorol 1987; 38: 185-202.

[23] Chen F, Dudhia J. Coupling an advanced land surface-hydrology model with the Penn State-NCAR MM5 Modeling system. Part II: Preliminary model validation. Mon Weather Rev 2001; 129: 587604.

[24] Chen F, Mitchell K. Using GEWEX/ISLSCP forcing data to simulate global soil moisture fields and hydrological cycle for 1987-1988. J Meteorol Soc Japan 1999; 77: 1-16.

[25] Jacquemin B, Noilhan J. Sensitivity study and validation of a land surface parameterization using the HAPEX-MOBILHY data set Boundary Layer Meteorol 1990; 52: 93-134.

[26] Schaake JC, Koren VI, Duan QY, Mitchell K, Chen F. A simple water balance model (SWB) for estimating runoff at different spatial and temporal scales. J Geophys Res 1996; 101: 7461-75.

[27] Zaitchik BF, Evans J, Smith RB. MODIS-derived boundary conditions for a mesoscale climate model: application to irrigated agriculture in the euphrates basin. Mon Weather Rev 2005; 133(6): 1727-43.

[28] Evans JP, Oglesby RJ, Lapenta WM. Time series analysis of regional climate model performance - art. no. D04104. J Geophys Res Atmos 2005, 110(D4): 4104.

[29] Zaitchik BF, Evans JP, Geerken RA, Smith RB. Climate and vegetation in the Middle East: inter-annual variability and drought feedbacks. J Climate 2007a; 20: 3924-41.

[30] Zaitchik BF, Evans JP, Smith RB. Regional impact of an elevated heat source: the Zagros Plateau of Iran. J Climate 2007b; 20: 413346.

[31] Kistler R, Kalnay E, Collins W, et al. The NCEP-NCAR 50-year reanalysis: Monthly means CD-ROM and documentation. Bull Am Meteorol Soc 2001; 82(2): 247-67.

[32] Ball GH, Hall DJ. A clustering technique for summarizing multivariate data. Behav Sci 1967; 12(2): 153-5. 